LISHAN SUN, Ph.D. ${ }^{1}$

(Corresponding author)

E-mail: Issun@bjut.edu.cn

QINGSHENG GONG, Master ${ }^{1}$

E-mail: gqsgentleman@sina.com

SIYUAN HAO, Master $^{1}$

E-mail: haosiyuan626@126.com

CHAO WANG, Ph.D. ${ }^{2}$

E-mail: 306597096@qq.com

YANYAN CHEN, Ph.D.1

E-mail: cdyan@bjut.edu.cn

${ }^{1}$ Beijing Key Laboratory of Traffic Engineering,

Beijing University of Technology, 100 Pingleyuan,

Chaoyang District, 100124, Beijing, China

2 School of Economics and Management,

Beijing University of Technology, 100 Pingleyuan,

Chaoyang District, 100124, Beijing, China
Traffic in the Cities

Preliminary Communication

Submitted: 10 Dec. 2016

Accepted: 10 Oct. 2017

\title{
EXPERIMENTAL STUDY OF OBLIQUE PEDESTRIAN STREAMS
}

\begin{abstract}
The intersecting of pedestrian streams is a common phenomenon which would lead to the pedestrian deceleration, stopping, and even threat to the safety of walking. The organization of pedestrian flow is a critical factor which influences the intersection traffic. The aim of this paper is to study the characteristics of oblique pedestrian streams by a set of pedestrian experiments. Two groups of experiment participants, three volume levels and five intersecting angles were tested. The qualitative analysis and quantitative analysis methods were applied to find out the relationship between the pedestrian streams angle and pedestrian characteristics. The results indicated that the mean and median speed, exit traffic efficiency decreased initially and increased afterwards with the increase of intersecting angles when the volume was $1,000 \mathrm{p} / \mathrm{h} / \mathrm{m}$ and $3,000 \mathrm{p} / \mathrm{h} / \mathrm{m}$, while the speed standard deviation changing inversely. However, these four factors show the opposite variation tendency in volume $5,000 \mathrm{p} / \mathrm{h} / \mathrm{m}$. Meanwhile, the quadratic function was selected to fit them. It is found that the worst speeds of pedestrian streams were $131^{\circ}$ and $122^{\circ}$ in volume $1,000 \mathrm{p} / \mathrm{h} / \mathrm{m}$ and $3,000 \mathrm{p} / \mathrm{h} / \mathrm{m}$, respectively, and the greatest influence on pedestrian streams was $125^{\circ}$ in volume $5,000 \mathrm{p} / \mathrm{h} / \mathrm{m}$. The results of this research can help establish the foundation for the organization and optimization of intersecting pedestrian streams.
\end{abstract}

\section{KEY WORDS}

rail transit; intersecting pedestrian streams; intersecting angle; pedestrian experiment;

\section{INTRODUCTION}

With the rapid expansion of rail network, the rail transit passenger number has exploded in Beijing. Large crowds have become a more frequent phenomenon, which could lead to passenger conflicts. Intersecting of pedestrian streams is one of the typical flows that contribute to the large crowds. It leads to deceleration and stopping, which undermines the moving efficiency of passengers and the walking service level, and even presents the threat to the safety of walking. Although intersecting pedestrian streams are practically unavoidable, an efficient design of walking facilities or organization of pedestrian streams is particularly necessary to strengthen the intersection.

Since Fruin paid attention to the pedestrian traffic, the characteristics of pedestrian behaviour have become a research highlight over the past 40 years [1]. A variety of studies were conducted to investigate the self-organization phenomenon in intersecting streams, establish mathematical models which were used to describe the status of pedestrian streams, and also to analyze microcosmic characteristics of intersecting pedestrian streams. After Ando et al. [2] had made an investigation in which two pedestrian streams crossed each other at an oblique intersecting angle at a railway station and gave a simple explanation for this observed behaviour, studies had gradually focused on bidirectional pedestrian flows with an intersecting angle. Early research focused on the phenomenon of stripe formation by self-organization in intersection areas with simulation which described a distribution status of the same direction pedestrians [2-5]. In recent years, a few intersecting pedestrian stream models had been established to describe the state of motion [6-9] and analysed speed variation before and after pedestrian intersecting [9-12].

However, the past studies of the stripe formation phenomenon and theoretical pedestrian stream models were unable to reflect the real-world characteristics of the pedestrian behaviour. Field observation and pedestrian experiments were recognized as a more 
reliable approach [13-18]. Early studies used the perpendicular intersecting angle as a representative angle to observe the intersecting pedestrian behaviour [13, 14 and 19]. However, intersecting pedestrian streams also included other angles such as various oblique intersections, which are commonly seen in rail transit hallways. Travel speed was deemed as one of the most important traffic behaviour parameters in such studies, and some studies track pedestrian movements using various approaches [20-21]. Hediyeh et al. [15] used computer vision to track pedestrian movements for diagonal crossings at an intersection and found that the speed was higher during the pedestrian clearance interval than during the walk. Shiwakoti et al. [22] collected the pedestrian movement data from a busy crosswalk and pedestrian experiment to study the effects of varying angles from $45^{\circ}$ to $180^{\circ}$ of intersecting pedestrians. It was found that the speed of the reference stream decreased when the angle increased from $45^{\circ}$ to $180^{\circ}$, and it was also observed that the maximum disruption was induced when the angle was approximately $135^{\circ}$. Similarly, Shao also indicated that the speed variation before and after intersecting of pedestrian streams increased with the increase of intersecting angle from $30^{\circ}$ to $90^{\circ}$ through actual survey [16].

In summary, past studies involved both the macroscopic and microscopic levels. Some pilot studies analysed the impact of different intersecting angles on travel speed. Nevertheless, the existing studies were limited, lacking stable control factor, and the insights were superficial. The aim of this paper is to study the pedestrian characteristics of oblique pedestrian streams. The remainder of this paper is organized as follows. First the design of the controlled pedestrian experiment is described and the authenticity and effectiveness of experiment scenario are demonstrated. Then the pedestrian behaviour characteristics are analysed by qualitative and quantitative methods to find out the relationship between the pedestrian stream angles and pedestrian characteristics. The findings of this study are conducive for rail transit administration to optimize the passenger flow organization.

\section{DESIGN OF THE PEDESTRIAN EXPERIMENT}

A series of pedestrian experiments have been conducted in the courtyard of the Beijing University of Technology (BJUT) in the afternoon of April 17, 2015. Fifty totally healthy undergraduate students, who have satisfied the demands of the minimum sample size, were selected from the university as participantsin the experiment. The number of participants is sufficient to carry out all kinds of experiments. Considering that the familiarity among students may cause biased experiment results (e.g., chatting and frequent stops during experiment), they were selected from different classes and departments. Twenty-five participants were males and the remainder were females, and $19 \%$ of the participants were walking in groups according to the survey of five subway stations at different times. The age of the participants ranged from 18 to 25 .

The actual experiment scenario is shown in Figure 1, where the experiment region, preparation region, leaving region, starting line, pedestrian entrance and exit measurement locations are labelled. The experiment region is $10 \mathrm{~m} \times 10 \mathrm{~m}$ which reflects a typical pedestrian stream intersecting area in railway stations. The preparation region and leaving region are $2 \mathrm{~m} \times 1.5 \mathrm{~m}$ which are enclosed by four separation pillars. The experiment participants were supposed to start walking from the start line which was the edge of the preparation region. Two entrances and two exits were placed respectively at the edge of preparation region and the leaving region. Experiment scenarios were designed according to schemes shown in Figure 2. Referencing past relevant studies and considering the need of this study, five different angles: $30^{\circ}, 60^{\circ}, 90^{\circ}, 120^{\circ}$, and $150^{\circ}$ were elicited [10-11]. The participants started walking from the entrance and left from the exit. The arrows represent the pedestrian walking directions. The angle between arrows represents the intersecting of pedestrian streams.

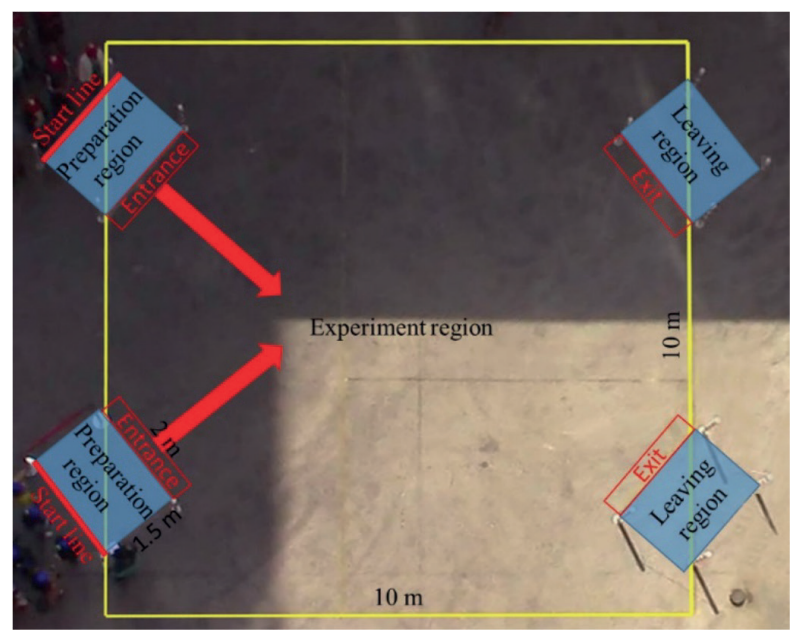

Figure 1 - Experiment scenario

The design of experiment volume was based on the Fruin level of service classification. According to Fruin, A-to-F 6 levels were used to represent the level of service in the passageway [1]. The description of the 6 levels is shown in Table 1 . When the level is above $\mathrm{B}$, minor conflicts would occur between pedestrians, passing and the speed being also restricted. In order to explore the impact of pedestrian volume on the pedestrian behaviour, three levels of the pedestrian volumes 1,000 p/h/m, 3,000 p/h/m and 5,000 p/h/m (equivalently $17 \mathrm{p} / \mathrm{min} / \mathrm{m}, 50 \mathrm{p} / \mathrm{min} / \mathrm{m}, 83 \mathrm{p} / \mathrm{min} / \mathrm{m}$ ), 


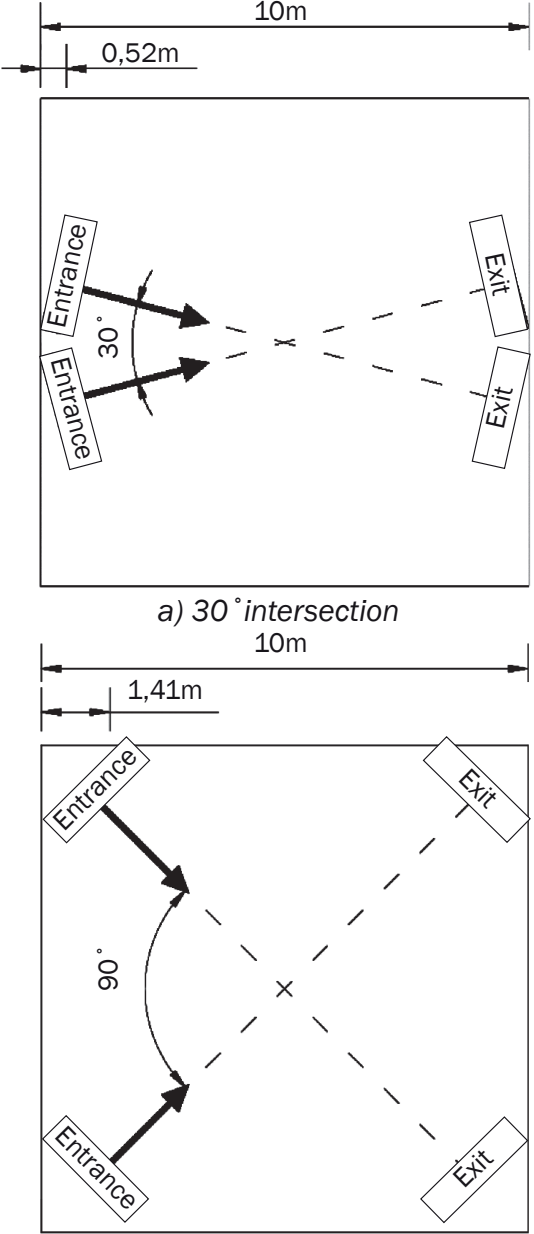

c) $90^{\circ}$ intersection

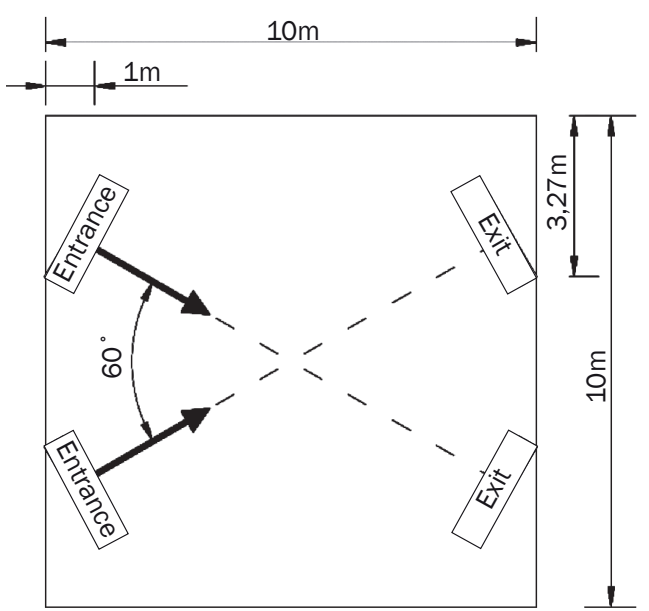

b) $60^{\circ}$ intersection $10 \mathrm{~m}$

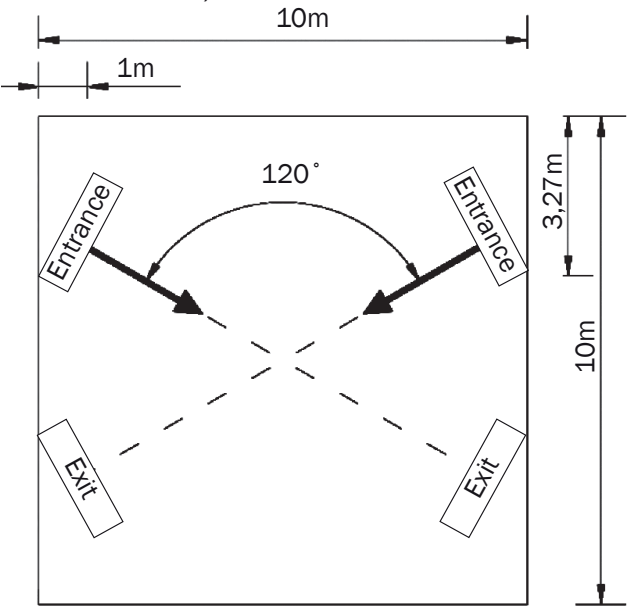

d) $120^{\circ}$ intersection

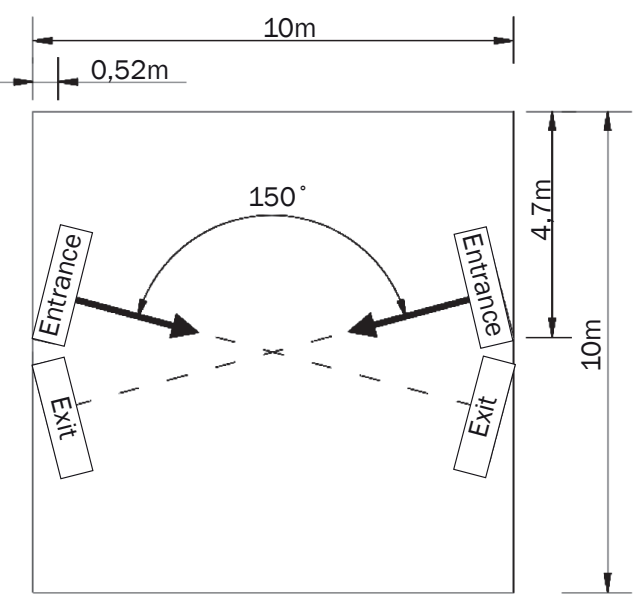

e) $150^{\circ}$ intersecting

Figure 2 - Design of different intersection angles

Table 1 - Passageway level of service descriptions [1]

\begin{tabular}{||c|c|l||}
\hline \hline Level of service & Volume $[\mathrm{p} / \mathrm{min} / \mathrm{m}]$ & \multicolumn{1}{|c||}{ Description } \\
\hline \hline A & $<23$ & Threshold of free flow, convenient passing, conflicts avoidable. \\
\hline B & $23-33$ & Minor conflicts, passing and speed restrictions \\
\hline C & $33-49$ & Crowded but fluid movement, passing restricted, cross and reverse flows difficult. \\
\hline D & $49-66$ & Significant conflicts, passing and speed restrictions, intermittent shuffling. \\
\hline E & $66-82$ & Shuffling walk; reverse, passing and cross flows very difficult; intermittent stopping. \\
\hline F & $>82$ & Critical density, flow sporadic, frequent stops, contacts with others. \\
\hline
\end{tabular}


were tested, which represent low, medium and high density flow according to Fruin level of service classification. At the same time, the experimental stream ratio was 1:1 without consideration of the unbalanced stream in this research. Thus, a total of 15 scenarios were set up for the analysis, as listed in Table 2.

The instruction phase was conducted before each experiment, and the lab staff introduced the walking direction and directed the destination of each pedestrian stream as seen in Figure 3a. Some important pieces of information were emphasized in this phase: (1) they need to assume themselves walking in subway scenario with some purposes such as going to school, going shopping, etc. (2) they barely knew each other. To distinguish different streams, caps with different colours were used. In order to prevent the instability of a single experiment, every experiment was conducted three times as shown in Figure $3 b$.

To extract the pedestrian behaviour in an automated fashion, a digital camera was placed above the experiment area, $20 \mathrm{~m}$ high. The digital camera had a resolution of $1,920 \times 1,080$ pixels and a frame capture rate of 30 frames per second, which was

Table 2 - Experiment scenario settings

\begin{tabular}{||c|c|c||}
\hline & $\begin{array}{c}\text { Angle of } \\
\left.\text { pedestrian streams [ }{ }^{\circ}\right]\end{array}$ & $\begin{array}{c}\text { Volume } \\
{[\mathrm{p} / \mathrm{h} / \mathrm{m}]}\end{array}$ \\
\hline \hline Scenario 1a & 30 & 1,000 \\
\hline Scenario 1b & 60 & 1,000 \\
\hline Scenario 1c & 90 & 1,000 \\
\hline Scenario 1d & 120 & 1,000 \\
\hline Scenario 1e & 150 & 1,000 \\
\hline Scenario 2a & 30 & 3,000 \\
\hline Scenario 2b & 60 & 3,000 \\
\hline Scenario 2c & 90 & 3,000 \\
\hline Scenario 2d & 120 & 3,000 \\
\hline Scenario 2e & 150 & 3,000 \\
\hline Scenario 3a & 30 & 5,000 \\
\hline Scenario 3b & 60 & 5,000 \\
\hline Scenario 3c & 90 & 5,000 \\
\hline Scenario 3d & 120 & 5,000 \\
\hline Scenario 3e & 150 & \\
\hline
\end{tabular}

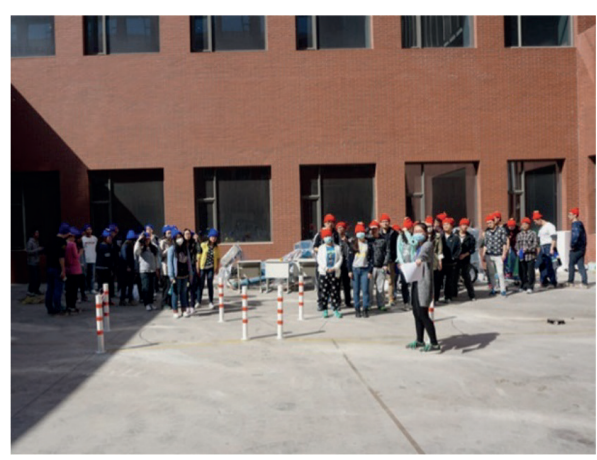

a) Instruction phase adequate to record the pedestrian behaviour [23]. SIMI Motion, which was a software application of using new algorithms to process video footage, provided an extensive platform for motion capture and 2D/3D movement analysis. When a pedestrian enters the scenario, movement track data which include position $(x, y)$, speed, and acceleration, etc. could be semi-automatedly marked.

Before the formal experiments, three trial experiments were conducted to compare the pedestrian speed of experiment flow and the actual subway flow, which is the most important pedestrian characteristic in this research. Trial experiments were conducted according to the extracted volume and the number of pedestrians from the subway videos. Using the one-way ANOVA, the comparing value is shown in Table 3.

Table 3 - Comparison of experimental and real environment

\begin{tabular}{|c|c|c|c|}
\hline \multirow{2}{*}{$\begin{array}{c}\text { Comparison of } \\
\text { scenario }\end{array}$} & \multicolumn{2}{|c|}{ Scenario setting } & \multirow{2}{*}{$\begin{array}{l}\text { Sig. of } \\
\text { speed }\end{array}$} \\
\hline & Volume & $\begin{array}{l}\text { Number of } \\
\text { pedestrians }\end{array}$ & \\
\hline Scenario 1 & 1,350 & 25 & 0.13 \\
\hline Scenario 2 & 2,050 & 25 & 0.11 \\
\hline Scenario 3 & 4,800 & 50 & 0.08 \\
\hline
\end{tabular}

The significance test in Table 3 revealed that there is no significant difference between the trial experiments and real-world subway hallways (Sig.>0.05), which demonstrates that the experiment could mimic the real-world scenario. Then, the pedestrian parameter data for different angle and different volume could be obtained from the experiment.

\section{QUALITATIVE ANALYSIS}

\subsection{Walking track with time mean speed}

As the basic parameter in pedestrian traffic, speed represents the walking distances in unit time [24]. Pedestrian speed includes time mean speed (TMS) and space mean speed (SMS). TMS is instantaneous

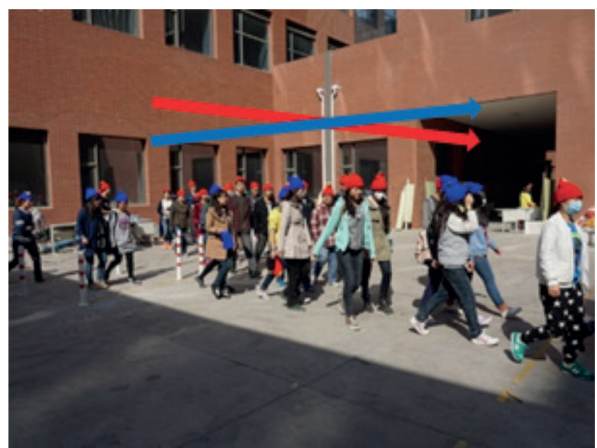

b) Experiment phase

Figure 3 - Pedestrian experiment phase 
speed of pedestrian to pass through the observation line in a certain time while space mean speed is an average speed of pedestrian in a section of distance. In order to describe the pedestrian walking track with speed expression in the entire experiment, TMS is quoted in this research. Meanwhile, according to
Hyman Law [25]: time elapsed of the human central nervous system to manage a 1-bit message is $0.13 \mathrm{~s}$, while the message quantity of a pedestrian who needs to decide whether or not to leave the expectation way is 1 bit. Therefore, the reflection time of a pedestrian to move is $0.13 \mathrm{~s}$.

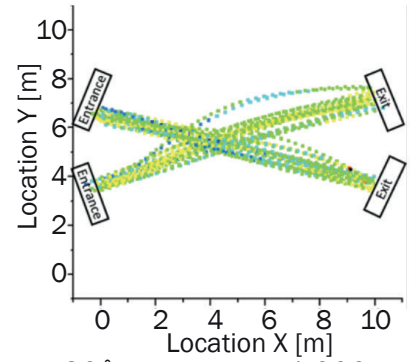

a) $30^{\circ}$ intersecting $(1,000 \mathrm{p} / \mathrm{h} / \mathrm{m})$

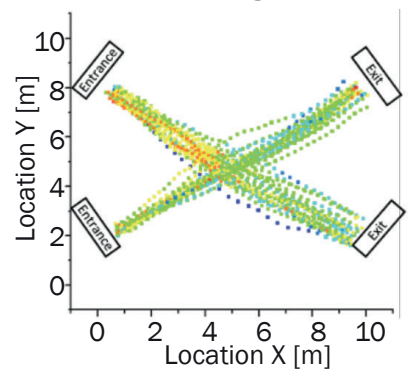

d) $60^{\circ}$ intersecting $(1,000 \mathrm{p} / \mathrm{h} / \mathrm{m})$

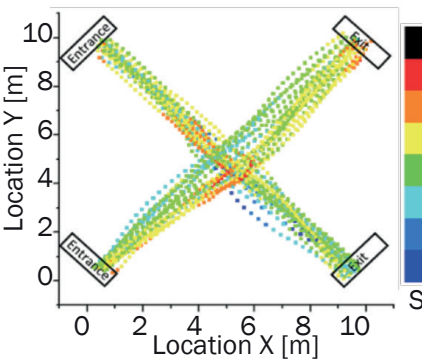

g) $90^{\circ}$ intersecting $(1,000 \mathrm{p} / \mathrm{h} / \mathrm{m})$

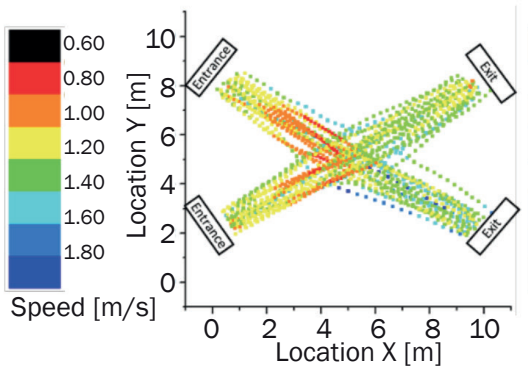

e) $60^{\circ}$ intersecting $(3,000 \mathrm{p} / \mathrm{h} / \mathrm{m})$

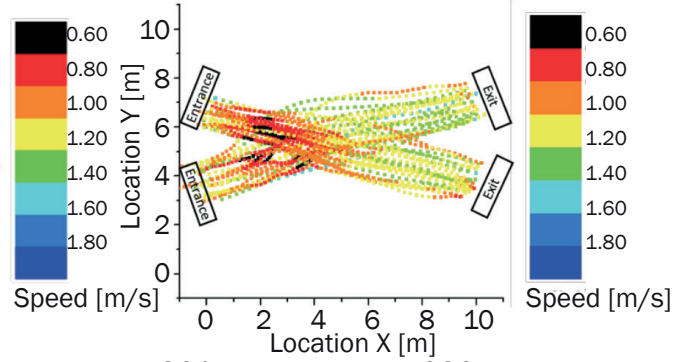

c) $30^{\circ}$ intersecting $(5,000 \mathrm{p} / \mathrm{h} / \mathrm{m})$

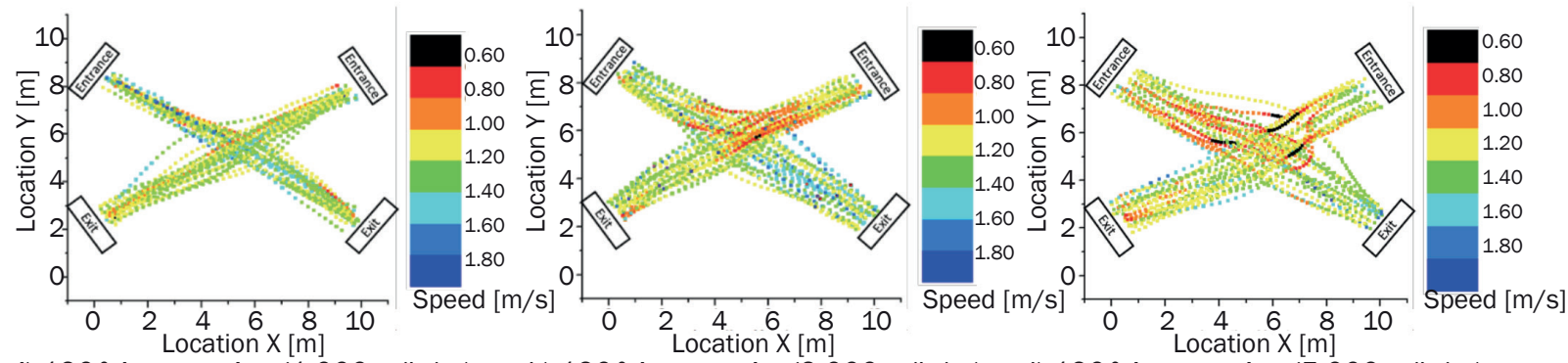

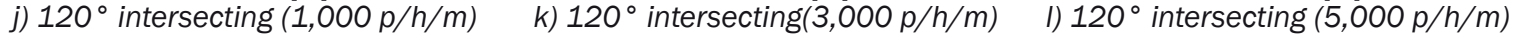

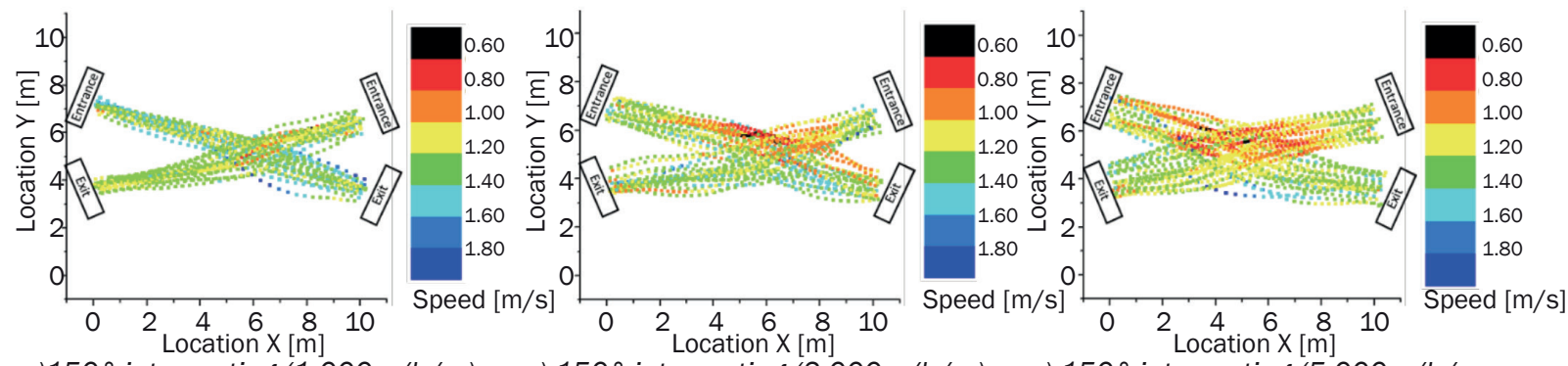

m) $150^{\circ}$ intersecting $(1,000 \mathrm{p} / \mathrm{h} / \mathrm{m})$

n) $150^{\circ}$ intersecting $(3,000 \mathrm{p} / \mathrm{h} / \mathrm{m})$

o) $150^{\circ}$ intersecting $(5,000 \mathrm{p} / \mathrm{h} / \mathrm{m}$

Figure 4 - Walking track with TMS of different angles and different volumes 
Figure 4 shows TMS at different intersecting angles for the three different volumes. Coloured points represent the pedestrian trajectory at different times. The colour of the points represents the pedestrian speed at different locations. Each line represents a pedestrian walking track. Colour gradients are used to represent the speed where black colour indicates the lowest, while dark blue means the highest speed. The speed can represent the degree of pedestrian conflict. The lower the speed, the more severe the pedestrians' conflict. Overall, the positions of lower speeds labelled black, red and orange are mostly distributed in intersecting areas and before the intersecting areas, especially the intersecting areas with the most serious of pedestrian conflicts.

Different volumes show different patterns of TMS with the change of intersecting angles. With the increase of pedestrian volume, TMS decreases, especially the TMS in position of the intersecting area. In the volume of $1,000 \mathrm{p} / \mathrm{h} / \mathrm{m}$ and $3,000 \mathrm{p} / \mathrm{h} / \mathrm{m}$, smaller TMS point is the least when the intersecting angle is $30^{\circ}$. This phenomenon indicates that small angle is beneficial to pedestrian in the smaller volumes. While the intersecting streams of $60^{\circ}$ to $150^{\circ}$ result in different degree conflicts, but the specific degree could not be explained from the figure. In the volume of $5,000 \mathrm{p} / \mathrm{h} / \mathrm{m}$, there is opposite result compared with volumes of $1,000 \mathrm{p} / \mathrm{h} / \mathrm{m}$ and $3,000 \mathrm{p} / \mathrm{h} / \mathrm{m}$. The numbers of small TMS points are highest in the angle of $30^{\circ}$.

\subsection{Walking direction and distance}

To explore the reason that different volumes reveal different patterns of TMS, screenshots of pedestrian walking direction in the intersecting area are shown in Figure 5. The directions of red arrows are consistent to the pedestrian walking direction, and the location of yellow arrows represent $X$ coordinates of pedestrians. At the smaller intersecting angle, smaller volumes of pedestrians would not cross the gap of other pedestrian streams immediately when two streams meet. They choose to walk forward to find the appropriate and sufficient gaps to cross. The time increment is $1 \mathrm{~s}$ from left to right. As can be seen in Figure $5 a$, the pedestrian walks for about $2 \mathrm{~m}$ in the direction of $X$ in the process of crossing. However, the pedestrian cannot walk forward because of the serried crowd in the intersecting areas in the bigger volumes. And they have to cross each other in the intersecting areas. If there is no sufficient gap to cross, they can only decelerate, even stop. As seen in Figure 5b, the pedestrian walking distances of $X$ direction are less than $1 \mathrm{~m}$. Therefore, small volumes are beneficial for pedestrians to walk in smaller intersecting angles of pedestrian streams, while it is opposite for large volumes.
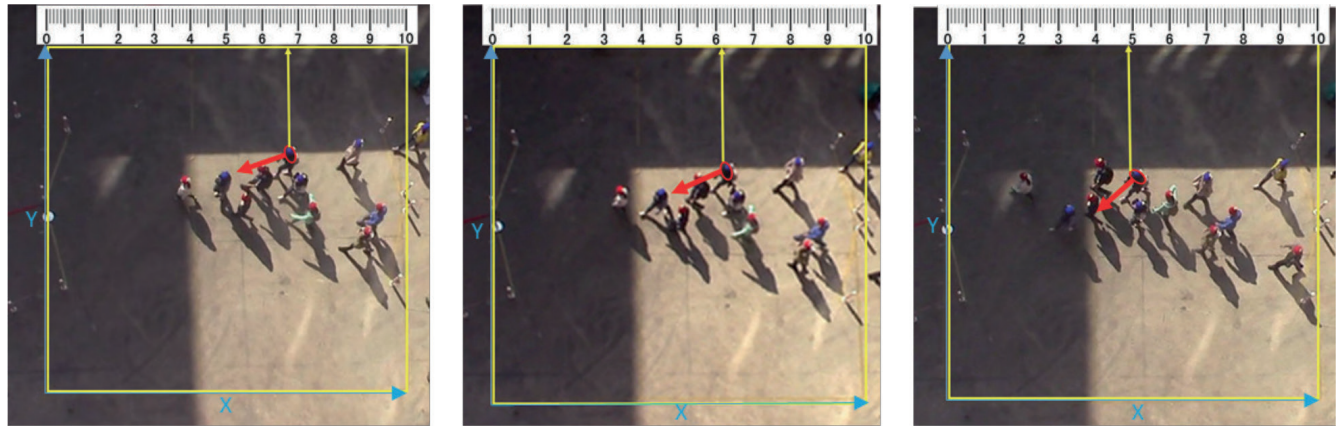

a) Pedestrian walking change with time in small volume (i.e. $3,000 \mathrm{p} / \mathrm{h} / \mathrm{m}$ )
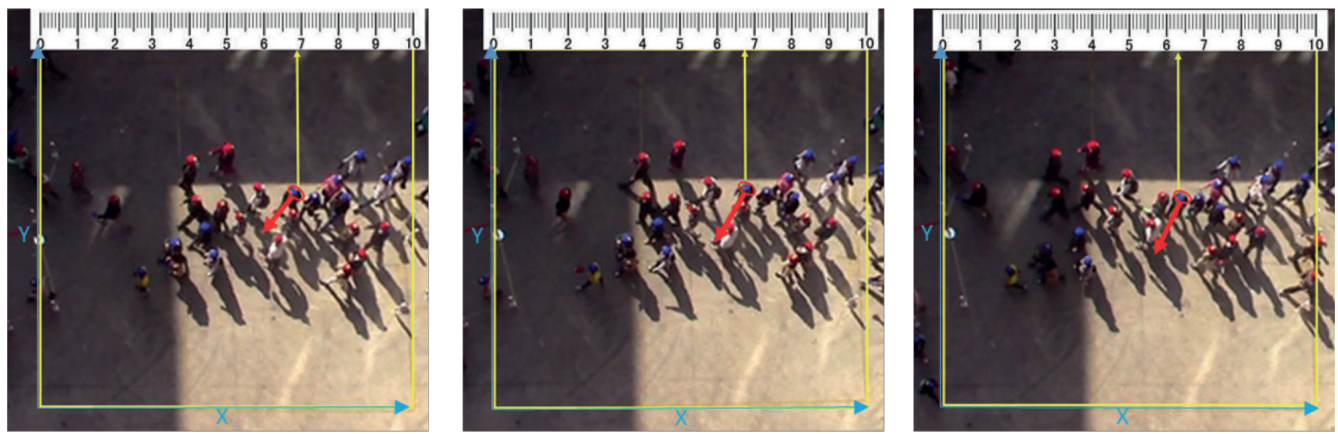

b) Pedestrian walking change with time in large volume (i.e. 5,000 p/h/m)

Figure 5 - Pedestrian walking direction and distance in intersecting area of $30^{\circ}$ angle 


\section{QUANTITATIVE ANALYSIS}

\subsection{Descriptive statistics of speed}

The previous section analyses qualitatively the pedestrian walking track with TMS and the change of pedestrian walking direction and distance in the intersecting area. In this section, quantitative analysis is conducted to further explore the impact of intersecting angles on oblique pedestrian streams. As seen in Table 4, the descriptive statistics of pedestrian streams speed under different volumes is obtained via SPSS analysis.

The mean speed and the median speed, and the standard deviation are of particular interest. Their changes are different under different volumes with the increase of the intersecting angle. When the volume is $1,000 \mathrm{p} / \mathrm{h} / \mathrm{m}$ and $3,000 \mathrm{p} / \mathrm{h} / \mathrm{m}$, the mean and the median speed decrease initially and increase afterwards with the increase of the intersecting angles. Also, the speed standard deviation first increases and then decreases. However, the mean speed, median speed and the standard deviation speed show the opposite variation tendency in volume of $5,000 \mathrm{p} / \mathrm{h} / \mathrm{m}$ compared with two smaller volumes. For all volumes, the extreme points appear when the angle is $120^{\circ}$.

When the volumes are $1,000 \mathrm{p} / \mathrm{h} / \mathrm{m}$ and 3,000 $\mathrm{p} / \mathrm{h} / \mathrm{m}$, because of the sufficient gap between two pedestrians before and after, it is convenient for pedestrians of other directions to pass through the gap. The change trend of the mean speed and the median speed is explained as follows:
1) When the angles change from $30^{\circ}$ to $90^{\circ}$, two pedestrian streams have the same destination [11]. The smaller the intersecting angle, the smaller the difference of the walking direction. At the same time, even the pedestrians cannot see the gap easily at a smaller angle; they do not need to cross the gap immediately, but rather walk forward to find the appropriate gap to cross. Therefore, with the intersecting angles reduced, the mean speed and the median speed increase.

2) When the angle changes from $90^{\circ}$ to $120^{\circ}$, there are two opposing effects on the pedestrian speed. The first effect is that the pedestrian must zigzag to avoid other pedestrians who are coming from the other direction [11] compared with the straight line of $90^{\circ}$. This effect is more dominant for decreasing the speed. The second effect is an increase of speed due to the obvious gap of pedestrian view in case of obtuse intersecting angle.

3) When the angle changes from $120^{\circ}$ to $150^{\circ}$, which is close to $180^{\circ}$, the pedestrian streams are prone to get self-organized which leads the pedestrian walking forward to find the appropriate gap to cross. Thus, the mean speed and the median speed increase.

When the volume is $5,000 \mathrm{p} / \mathrm{h} / \mathrm{m}$, the reasons of opposite variation tendency are explained as follows:

1) When the angles change from $30^{\circ}$ to $90^{\circ}$, the pedestrian cannot walk forward because of the serried crowd in the intersecting areas, although the intersecting angle is smaller. Pedestrians cannot find the gap easily at a smaller angle and have to decelerate.

Table 4 - Descriptive statistics of speed with different volumes

\begin{tabular}{|c|c|c|c|c|c|c|c|}
\hline $\begin{array}{l}\text { Volume } \\
{[p / h / m]}\end{array}$ & Angle $\left[{ }^{\circ}\right]$ & $\begin{array}{l}\text { Mean } \\
{[\mathrm{m} / \mathrm{s}]}\end{array}$ & $\begin{array}{c}\text { Median } \\
{[\mathrm{m} / \mathrm{s}]}\end{array}$ & $\begin{array}{c}\operatorname{Max} \\
{[\mathrm{m} / \mathrm{s}]}\end{array}$ & $\begin{array}{c}\operatorname{Min} \\
{[\mathrm{m} / \mathrm{s}]}\end{array}$ & $\begin{array}{l}\text { Std. } \\
{[\mathrm{m} / \mathrm{s}]}\end{array}$ & $\begin{array}{c}\text { Pedestrian traffic } \\
\text { efficiency } \\
{[\mathrm{p} / \mathrm{h} / \mathrm{m}]}\end{array}$ \\
\hline \multirow{5}{*}{1,000} & 30 & 1.32 & 1.32 & 1.84 & 0.54 & 0.25 & 2,300 \\
\hline & 60 & 1.28 & 1.26 & 1.87 & 0.75 & 0.27 & 2,123 \\
\hline & 90 & 1.24 & 1.25 & 1.77 & 0.72 & 0.28 & 2,019 \\
\hline & 120 & 1.22 & 1.23 & 1.87 & 0.83 & 0.30 & 1,882 \\
\hline & 150 & 1.23 & 1.28 & 1.88 & 0.55 & 0.26 & 1,925 \\
\hline \multirow{5}{*}{3,000} & 30 & 1.23 & 1.23 & 1.77 & 0.68 & 0.25 & 3,067 \\
\hline & 60 & 1.18 & 1.18 & 1.86 & 0.67 & 0.31 & 2,760 \\
\hline & 90 & 1.16 & 1.19 & 1.78 & 0.56 & 0.36 & 2,509 \\
\hline & 120 & 1.14 & 1.14 & 1.89 & 0.70 & 0.40 & 2,587 \\
\hline & 150 & 1.15 & 1.16 & 1.82 & 0.48 & 0.35 & 2,588 \\
\hline \multirow{5}{*}{5,000} & 30 & 0.92 & 0.95 & 1.77 & 0.48 & 0.37 & 3,184 \\
\hline & 60 & 1.02 & 1.05 & 1.87 & 0.53 & 0.43 & 3,600 \\
\hline & 90 & 1.07 & 1.08 & 1.70 & 0.42 & 0.47 & 3,764 \\
\hline & 120 & 1.09 & 1.05 & 1.88 & 0.52 & 0.49 & 4,158 \\
\hline & 150 & 1.08 & 1.05 & 1.88 & 0.62 & 0.41 & 4,140 \\
\hline
\end{tabular}


2) When the angle changes from $90^{\circ}$ to $120^{\circ}$, the reasons are the same as for the volumes of 1,000 $\mathrm{p} / \mathrm{h} / \mathrm{m}$ and $3,000 \mathrm{p} / \mathrm{h} / \mathrm{m}$. The difference is that the obvious gap is more effective to the crossing path.

3 When the angle changes from $120^{\circ}$ to $150^{\circ}$, although the gap is easy to see the pedestrians will tend to walk forward to find the appropriate gap and the phenomenon of a zigzag path becomes increasingly prominent because of the high density in the intersecting areas. Thus, the mean and the median speed decrease with an increase of the angle.

However, there is little information which can be read from the max and min speeds. The max speed is distributed from $1.77 \mathrm{~m} / \mathrm{s}$ to $1.89 \mathrm{~m} / \mathrm{s}$, while the $\mathrm{min}$ speed changes from $0.42 \mathrm{~m} / \mathrm{s}$ to 0.70 . This happens because they cannot reflect the pattern of pedestrian streams. The min speed of volume $5,000 \mathrm{p} / \mathrm{h} / \mathrm{m}$ is smaller than for other volumes, which indicates that the larger volume could largely reduce some pedestrians' speeds.

\subsection{The relationship between pedestrian speed and pedestrian streams angle}

Figure 6 and Table 5 show the concrete quantification of the relationship between the speed and the angle of pedestrian streams. At the same time, quadratic function is selected to fit them. The R2 is over 0.96 for all the volumes. Extreme coordinates of speed fluctuate from $120^{\circ}$ to $150^{\circ}$ in different volumes which indicate that the change of speed with pedestrian streams angle is different. The worst speeds to pedestrian streams are at the angles of $131^{\circ}$ and $122^{\circ}$ in volume of $1,000 \mathrm{p} / \mathrm{h} / \mathrm{m}$ and $3,000 \mathrm{p} / \mathrm{h} / \mathrm{m}$, respectively. This result is similar to Wong's research which indicated that the maximum disruption was approximately at $135^{\circ}$ [11]. However, the greatest influence on pedestrian streams is at $125^{\circ}$ in the volume of 5,000 $\mathrm{p} / \mathrm{h} / \mathrm{m}$ which is different from Wong's research. This is because the volume of research was discrepant. Therefore, the relevant departments should adopt different control measures of passenger flow organization for different pedestrian volumes.

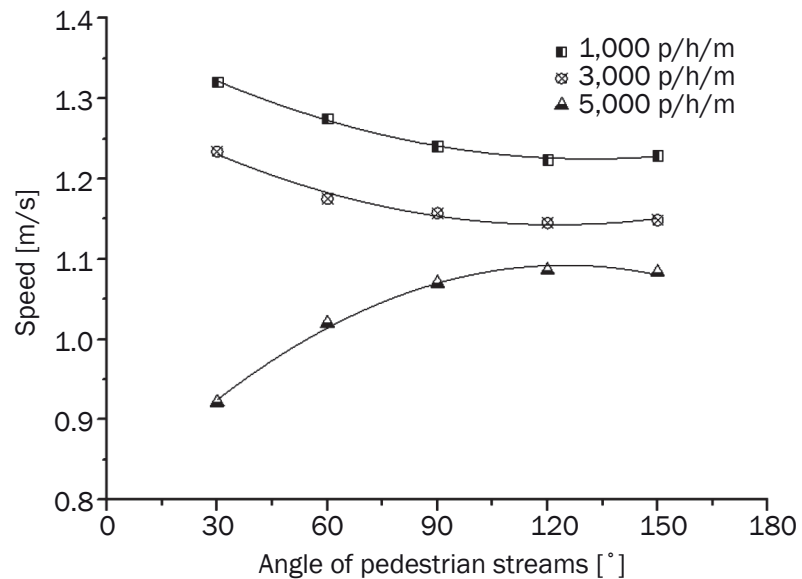

Figure 6 - The relationship between pedestrian speed and pedestrian streams angle

Pedestrian streams traffic efficiency reflects the space usage condition which is the number of people in the unit width under a time interval. The analysis of pedestrian streams traffic efficiency in experiment exit could judge the passing situation after crossing the intersecting region. The exit pedestrian streams traffic efficiency is calculated as:

$E=\frac{3,600}{t} \cdot \frac{n}{w}=\frac{3,600}{t_{n}-t_{1}} \cdot \frac{n}{w}$

where $E=$ exit pedestrian streams traffic efficiency $[\mathrm{p} / \mathrm{h} / \mathrm{m}] ; n=$ total number of pedestrians; $t=$ passing time of the entire pedestrian stream [s]; $t_{n}=$ time of number $n$ persons passing through the exit [s]; $w=$ exit width $[\mathrm{m}]$

The relationship between exit pedestrian streams traffic efficiency and pedestrian streams angle is shown in Figure 7 . It should be noted that experiment volumes which include 1,000 $\mathrm{p} / \mathrm{h} / \mathrm{m}, 3,000 \mathrm{p} / \mathrm{h} / \mathrm{m}$, $5,000 \mathrm{p} / \mathrm{h} / \mathrm{m}$ express traffic efficiency of entrance. Because of the influence of pedestrian intersecting, the traffic efficiency of exit and entrance are different. It is obvious that the exit pedestrian streams traffic efficiency is smaller than the volume of entrance of $5,000 \mathrm{p} / \mathrm{h} / \mathrm{m}$, and it is almost equal in $3,000 \mathrm{p} / \mathrm{h} / \mathrm{m}$; but the exit traffic efficiency is better than the volume of entrance of $1,000 \mathrm{p} / \mathrm{h} / \mathrm{m}$. This is because the intersecting will seriously influence the pedestrian walking in bigger volume which leads to decrease of traffic efficiency. However, the pedestrian will walk faster with

Table 5 - Fitting formula of speed and angle for different volumes

\begin{tabular}{||c|c|c|c||}
\hline \hline Volume $[\mathrm{p} / \mathrm{h} / \mathrm{m}]$ & Fitting formula of speed $(y)$ and angle $(x)$ & $\mathrm{R}^{2}$ & Extreme \\
\hline \hline 1,000 & $y=9.45315 \cdot 10^{-6} x^{2}-0.00248 x+1.38802$ & 0.99599 & 131 \\
\hline 3,000 & $y=1.02508 \cdot 10^{-5} x^{2}-0.00251 x+1.29664$ & 0.96303 & 122 \\
\hline 5,000 & $y=-1.87264 \cdot 10^{-5} x^{2}+0.00467 x+0.80148$ & 0.99049 & 125 \\
\hline
\end{tabular}


Sun L, Gong Q, Hao S, Wang C, Chen Y. Experimental Study of Oblique Pedestrian Streams

Table 6 - Fitting formula of exit pedestrian streams traffic efficiency and angle in different volumes

\begin{tabular}{|c|c|c|}
\hline Volume $[\mathrm{p} / \mathrm{h} / \mathrm{m}]$ & Fitting formula of exit traffic efficiency $(y)$ and angle $(x)$ & $\mathrm{R}^{2}$ \\
\hline \hline 1,000 & $y=0.03232 x^{2}-9.11808 x+2550.64817$ & 0.9527 \\
\hline 3,000 & $y=0.07481 x^{2}-17.23589 x+3512.72727$ & 0.9156 \\
\hline 5,000 & $y=-0.05047 x^{2}+17.31369 x+2710.66176$ & 0.9373 \\
\hline
\end{tabular}

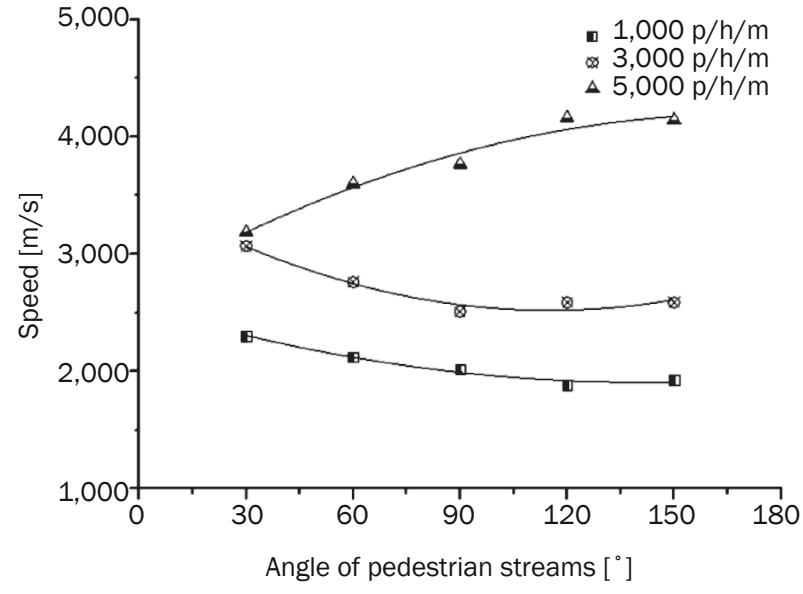

Figure 7 - The relationship between exit pedestrian streams traffic efficiency and pedestrian streams angle

less influence of other people in the volume of 1,000 $\mathrm{p} / \mathrm{h} / \mathrm{m}$. Thus, exit traffic efficiency is greater, even over $2,000 \mathrm{p} / \mathrm{h} / \mathrm{m}$.

Meanwhile, the same as the speed, with the increase of pedestrian stream angles the variation trend of exit pedestrian streams traffic efficiency decreases first and then increases slightly afterward in the volume of $1,000 \mathrm{p} / \mathrm{h} / \mathrm{m}$ and $3,000 \mathrm{p} / \mathrm{h} / \mathrm{m}$, and increases first and decreases slightly afterwards in the volume of $5,000 \mathrm{p} / \mathrm{h} / \mathrm{m}$. Table 6 shows the quantification relationship between the exit traffic efficiency and the angle of pedestrian streams. To fit them, a quadratic function is used with $\mathrm{R}^{2}$ over 0.91 .

Overall, when the pedestrian streams intersecting is unavoidable, smaller intersecting angle should be designed in smaller volume while bigger intersecting angle should be used in larger volume, which could improve the traffic efficiency in the subway station and public place.

\section{CONCLUSIONS AND RECOMMENDATIONS}

This paper studies the pedestrian characteristics of oblique pedestrian streams from the pedestrian experiments. Three volume levels and five intersecting angles were tested. By analysis of the pedestrian behaviour parameters through qualitative and quantitative method to find the relationship between the pedestrian streams angle and pedestrian characteristics, the following conclusions have been drawn.
- Qualitative research analyzes the walking track with speed as well as times, which indicates that small angle is beneficial to pedestrians in the volume of 1,000 or $3,000 \mathrm{p} / \mathrm{h} / \mathrm{m}$, while small angle is terrible in the volume of $5,000 \mathrm{p} / \mathrm{h} / \mathrm{m}$. This is because different pedestrians are reflected in small intersecting angle. Smaller volumes of pedestrians would walk forward to find the appropriate and sufficient gaps to cross, while bigger volumes of pedestrians have to cross the gap at present for serried intersecting areas which lead to deceleration and even stopping.

- Quantitative analysis is used to compare the difference of the value of speed descriptive statistics and pedestrian streams traffic efficiency in different volumes and angle settings. When the volume is $1,000 \mathrm{p} / \mathrm{h} / \mathrm{m}$ and $3,000 \mathrm{p} / \mathrm{h} / \mathrm{m}$, the mean speed, median speed and traffic efficiency decrease initially and increase afterwards with the increase of intersecting angles, and the speed standard deviation first increases and then decreases. However, the volume of $5,000 \mathrm{p} / \mathrm{h} / \mathrm{m}$ has the opposite variation tendency. This result is caused by different effects on the follow factors: pedestrian self-organization, pedestrian view, walking direction, crossing path, etc.

- Meanwhile, quantitative research obtains the analytical expression of quadratic function between the mean speed, exit pedestrian streams traffic efficiency and intersecting angle by using the curve-fitting method. It is found that the worst speed for pedestrian streams is at $131^{\circ}$ and $122^{\circ}$ in volumes of $1,000 \mathrm{p} / \mathrm{h} / \mathrm{m}$ and 3,000 $\mathrm{p} / \mathrm{h} / \mathrm{m}$, respectively, and the greatest influence on pedestrian streams is at $125^{\circ}$ in volume of $5,000 \mathrm{p} / \mathrm{h} / \mathrm{m}$.

The results can be applied to optimize the intersecting pedestrian streams, which is beneficial to provide the data support of promoting the moving efficiency of passengers as well as the walking service level. In addition, it is also good for rail transit to decrease the intersecting conflict severity, which is conducive for developing theoretical basis and practical reference for subway station designers and managers.

However, it should be noted that this study only focused on the pedestrian stream intersecting angle. In other words, the two-stream volume is assumed to be the same, and the experiment setting volume is restrictive within $5,000 \mathrm{p} / \mathrm{h} / \mathrm{m}$. It should also be noted that the participants in experiment did not include the disabled. To fully mimic the real-world situation, it is recommended to include in the future study also unbalanced flow ratio, larger volumes, and various types of pedestrians. 


\section{ACKNOWLEGEMENT}

The authors would like to acknowledge the financial support for this study provided by the National Natural Science Foundation of China (No. 51308017), Beijing Nova Program (Grant No. Z141106001814110), Key Program of Beijing Municipal Natural Science Foundation (NO. 4181002), Science and Technology Program of Beijing (Grant No. D161100005616001), and Beijing Higher Education Young Elite Teacher Project (YETP1216).

\section{孙立山 宫庆胜 郝思源 王超 陈艳艳}

\section{交叉行人流实验研究}

\section{摘要}

客流交叉是一种普遍存在的现象，会导致行人减速、 停止, 甚至对行人安全产生威胁, 行人流组织会影响交叉 交通。本文通过行人实验的方式研究行人流特性, 选取两 组实验人员、三种客流量以及五种交叉角度进行实验。 利用定性和定量分析的方式探求行人流交叉角度与行人 特性之间的关系。结果表明, 当交叉客流量为 $1000 \mathrm{p} / \mathrm{h} / \mathrm{m}$ 和 $3000 \mathrm{p} / \mathrm{h} / \mathrm{m}$ 时，随着相交角度的增大，平均速度、中位 速度以及交通效率呈现先减小后增大的趋势, 但是速度标 准差呈现相反的变化趋势; 另外, 当客流量为 $5000 \mathrm{p} / \mathrm{h} / \mathrm{m}$ 时, 四项指标又呈现正好相反的趋势。同时，通过拟合分 析发现当客流量为 $1000 \mathrm{p} / \mathrm{h} / \mathrm{m}$ 时, 相交角度 $131^{\circ}$ 效果较 差, 当客流量为 $3000 \mathrm{p} / \mathrm{h} / \mathrm{m}$ 时, 相交角度 $122^{\circ}$ 效果较差, 而当客流量为 $5000 \mathrm{p} / \mathrm{h} / \mathrm{m}$ 时, 相交角度 $125^{\circ}$ 对行人流影响 最大。本研究可为相交行人流组织优化提供科学依据。

\section{关键词:}

轨道交通, 交叉行人流, 交叉角度, 行人实验

\section{REFERENCES}

[1] Fruin JJ. Pedestrian planning and design. Metropolitan Association of Urban Designers \& Environmental Planners. 1971.

[2] Ando K, Ota H, and Oki T. Forecasting the flow of people. Railway Res. Rev. 1988;45(8): 8-14 (in Japanese).

[3] Dzubiella J, Löwen H. Pattern formation in driven colloidal mixtures: tilted driving forces and re-entrant crystal freezing. Journal of Physics Condensed Matter. 2002;14(40): 9383-9395(13). Available from: doi:10.1088/0953-8984/14/40/324 [Accessed $28^{\text {th }}$ November 2017].

[4] Hoogendoorn S, Piet HLB. Simulation of pedestrian flows by optimal control and differential games. Optimal Control Applications \& Methods. 2003;24(3): 153-172. Available from: doi:10.1002/oca.727 [Accessed $28^{\text {th }}$ November 2017].

[5] Hoogendoorn S, Daamen W. Self-organization in pedestrian flow. Traffic \& Granular Flow. 2005: 373-382. Available from: doi:10.1007/3-540-28091-X_36 [Accessed $28^{\text {th }}$ November 2017].

[6] Jiang $\mathrm{Y}$, Xiong T, Wong SC, Shu CW, Zhang M, Zhang P, Lam WHK. A reactive dynamic continuum user equilibrium model for bi-directional pedestrian flows. Acta
Mathematica Scientia. 2009;29(6): 1541-1555. Available from: doi:10.1016/S0252-9602(10)60002-1 [Accessed 28 $8^{\text {th }}$ November 2017].

[7] Xia Y, Wong SC, Shu CW, Zhang M, Lam WHK, Huang L. Dynamic continuum model for bi-directional pedestrian flows. Engineering \& Computational Mechanics. 2009;162(2): 67-75. Available from: doi:10.1680/ eacm.2009.162.2.67 [Accessed $28^{\text {th }}$ November 2017].

[8] Xiong T, Zhang M, Shu CW, Wong SC, Zhang P. High-order computational scheme for a dynamic continuum model for bi-directional pedestrian flows. Computeraided Civil \& Infrastructure Engineering. 2011;26(4): 298-310. Available from: doi:10.1111/j.14678667.2010.00688.x [Accessed 28 $8^{\text {th }}$ November 2017].

[9] Sharifi MS, Dan S, Christensen K, Chen A. Exploring traffic flow characteristics and walking speeds of heterogeneous pedestrian stream involving individuals with disabilities in different walking environments[C]// Transportation Research Board 95 ${ }^{\text {st }}$ Annual Meeting; 2015.

[10] Wong SC, Asce M, Leung WL, Chan SH, Lam WHK, Yung NHC, et al. Bidirectional pedestrian stream model with oblique intersecting angle. Journal of Transportation Engineering. 2010;136(3): 234-242. Available from: doi:10.1061/ASCETE.1943-5436.0000086 [Accessed $28^{\text {th }}$ November 2017].

[11] Xie S, Wong SC, Lam WHK, Chen A. Development of a bidirectional pedestrian stream model with an oblique intersecting angle. Journal of Transportation Engineering. 2013;139(7): 678-685. Available from: doi:10.1061/(ASCE)TE.1943-5436.0000555 [Accessed 28 $8^{\text {th }}$ November 2017].

[12] Lian L, Mai X, Song W, Richard YKK, Wei X, Jian. An experimental study on four-directional intersecting pedestrian flows. Journal of Statistical Mechanics Theory \& Experiment. Aug 2015. Available from: doi:10.1088/1742-5468/2015/08/P08024 [Accessed $28^{\text {th }}$ November 2017]

[13] Daamen W, Hoogendoorn SP. Experimental research of pedestrian walking behavior. Transportation Research Record Journal of the Transportation Research Board. 2003;1828: 20-30. Available from: doi:10.3141/1828-03 [Accessed 28 ${ }^{\text {th }}$ November 2017].

[14] Helbing D, Werner T. Self-organized pedestrian crowd dynamics: experiments, simulations, and design solutions. Transportation Science. 2005;39(1): 1-24. Available from: doi:10.1287/trsc.1040.0108 [Accessed $28^{\text {th }}$ November 2017].

[15] Hediyeh H, Sayed T, Zaki MH, Ismail K. Before and After Analysis of Pedestrian Crossing Speed Behavior at Scramble Phase Signalized Intersections. Transportation Research Board 91 ${ }^{\text {st }}$ Annual Meeting. 2012. Available from: doi:10.1080/15568318.2012.70809 8 [Accessed 28 ${ }^{\text {th }}$ November 2017].

[16] Shao Y, Shao W, Zhang N, et al. Influence of intersecting angles pedestrian streams for traffic capacity in subway station. Journal of highway and transportation research and development. 2013;11: 413-416.

[17] Sun L, Luo W, Yao L, et al. A comparative study of funnel shape bottlenecks in subway stations. Transportation Research Part A Policy \& Practice. 2017;98: 14-27. Available from: doi:https://doi.org/10.1016/ 
j.tra.2017.01.021 [Accessed 28 ${ }^{\text {th }}$ November 2017].

[18] Sun L, Hao S, Gong Q, et al. Pedestrian roundabout improvement strategy in subway stations. Transport. 2017: 1-10. Available from: doi:10.1680/ jtran.16.00073 [Accessed 28 ${ }^{\text {th }}$ November 2017].

[19] Jinkui L, Xianke W, Wenjing L. The Effects of Different Excavation Angle on Intersecting Tunnel Surrounding Rock Stability. $2^{\text {nd }}$ International Conference on Modelling, Identification and Control. Atlantis Press. 2015. Available from: doi:10.2991/mic-15.2015.57 [Accessed 28 $8^{\text {th }}$ November 2017].

[20] Wei Y, Tian Q, Guo T. An Improved Pedestrian Detection Algorithm Integrating Haar-Like Features and HOG Descriptors. Advances in Mechanical Engineering (Hindawi Publishing Corporati. 2013;2013(4): 546206546206. Available from: doi:10.1155/2013/546206 [Accessed 28 ${ }^{\text {th }}$ November 2017].

[21] Wei Y, Guo T, Tian Q, Miao X. Review on Vision Based Road Target Detection, Identification, and Tracking.
Journal of Beijing Institute of Technology. 2012;21(2): 257-262.

[22] Shiwakoti N, Gong Y, Shi X, Ye Z. Examining influence of merging architectural features on pedestrian crowd movement. Safety Science. 2015;75: 15-22. Available from: doi:https://doi.org/10.1016/j.ssci.2015.01.009 [Accessed 28 $8^{\text {th }}$ November 2017].

[23] Sun L, Yang Z, Rong J, Liu X. Study on the weaving behavior of high density bidirectional pedestrian flow. Mathematical Problems in Engineering. 2014;26(1): 1-9. Available from: doi:10.1155/2014/765659 [Accessed $28^{\text {th }}$ November 2017].

[24] Ren F, Liu X, Rong J. Traffic engineering. China communications press; 2003.

[25] Hyman R. Stimulus information as a determinant of reaction time. Journal of Experimental Psychology. 1953;45(3): 188-96. Available from: doi:10.1037/ h0056940 [Accessed 28 ${ }^{\text {th }}$ November 2017]. 